\title{
Intramuscular Bleeding Triggered by Disseminated Intravascular Coagulation with Enhanced Fibrinolysis in a Patient with Prostate Cancer: A Case Report
}

\author{
Eri Takada ${ }^{1}$, Seiji Adachi $^{1}$, Yohei Horibe ${ }^{1}$ and Masahito Shimizu ${ }^{2}$
}

\begin{abstract}
:
Disseminated intravascular coagulation (DIC) is the most frequent coagulation disorder associated with solid tumors, including prostate cancer. We herein report a 76-year-old man who suffered from intramuscular bleeding of the right gluteus maximus. Laboratory data showed a pattern of DIC with enhanced fibrinolysis, and a general examination led to the diagnosis of advanced prostate cancer with multiple bone metastases. To our knowledge, this is the first report describing intramuscular bleeding as an initial manifestation of prostate cancer with DIC with enhanced fibrinolysis.
\end{abstract}

Key words: DIC, fibrinolysis, fibrinolytic, prostate cancer, intramuscular bleeding

(Intern Med Advance Publication)

(DOI: 10.2169/internalmedicine.7697-21)

\section{Introduction}

Disseminated intravascular coagulation (DIC) is a serious complication in the presence of underlying disease, including solid tumors. There are three types of DIC, which are categorized according to the degree of fibrinolytic activation: DIC with suppressed fibrinolysis, DIC with enhanced fibrinolysis, and an intermediate pathogenesis between the two entities, DIC with balanced fibrinolysis (1). The appropriate diagnosis of DIC and successful treatment of the underlying malignancy can result in the improvement of the survival rate.

We herein report a case in which intramuscular bleeding of the buttocks was triggered by DIC with enhanced fibrinolysis in a patient with progressive prostate cancer.

\section{Case Presentation}

A 76-year-old man was admitted to our hospital due to continuous right buttock pain that had persisted for 2 weeks. Extensive subcutaneous bleeding was observed from his hip to his back. Computed tomography (CT) revealed an intra- muscular mass of the right gluteus maximus.

A laboratory analysis revealed the following findings: platelet count, $11.6 \times 10^{4} / \mu \mathrm{L}$ (normal, $16-41 \times 10^{4} / \mu \mathrm{L}$ ); hemoglobin, $8.9 \mathrm{~g} / \mathrm{dL}$ (normal, 13-18 g/dL); prothrombin time (PT), 64.8\% (normal, 70\%-130\%); fibrinogen, $61.3 \mathrm{mg} / \mathrm{dL}$ (normal, $180-350 \mathrm{mg} / \mathrm{dL}$ ); fibrinogen degradation product (FDP), $253.7 \mu \mathrm{g} / \mathrm{mL}$ (normal, 0-5 $\mu \mathrm{g} / \mathrm{mL}$ ); D-dimer, 64.5 $\mu \mathrm{g} / \mathrm{mL}$ (normal, 0-1.0 $\mu \mathrm{g} / \mathrm{mL}$ ); thrombin-antithrombin complex (TAT), $102 \mathrm{ng} / \mathrm{mL}$ (normal, $<3.0 \mathrm{ng} / \mathrm{mL}$ ); and plasmin$\alpha 2$-plasmin inhibitor complex, (PIC) $11.0 \mu \mathrm{g} / \mathrm{mL}$ (normal: < $0.8 \mu \mathrm{g} / \mathrm{mL}$ ). The DIC score according to the criterion for the diagnosis of DIC established by the Japanese Society of Thrombosis and Hemostasis (JSTH) in 2017 was 8 points, and the patient was diagnosed with DIC. Since a high FDP/ D-dimer ratio in addition to the obvious elevation of PIC and TAT was observed, he was diagnosed with DIC with enhanced fibrinolysis (1).

Contrast-enhanced CT on administration showed the irregular enhancement of the prostate, and his prostatespecific antigen (PSA) level was $1,827 \mathrm{ng} / \mathrm{mL}$. Therefore, a prostate biopsy was performed, and he was diagnosed with adenocarcinoma (Gleason score: 9 points). Bone scintigraphy revealed widespread bone metastases. Based on these

${ }^{1}$ Department of Internal Medicine, Gifu-Seino Medical Center, Gihoku Kosei Hospital, Japan and ${ }^{2}$ First department of Internal Medicine, Gifu University Graduate School of Medicine, Japan

Received: April 6, 2021; Accepted: July 8, 2021; Advance Publication by J-STAGE: October 12, 2021

Correspondence to Dr. Eri Takada, nyentakada@yahoo.co.jp 


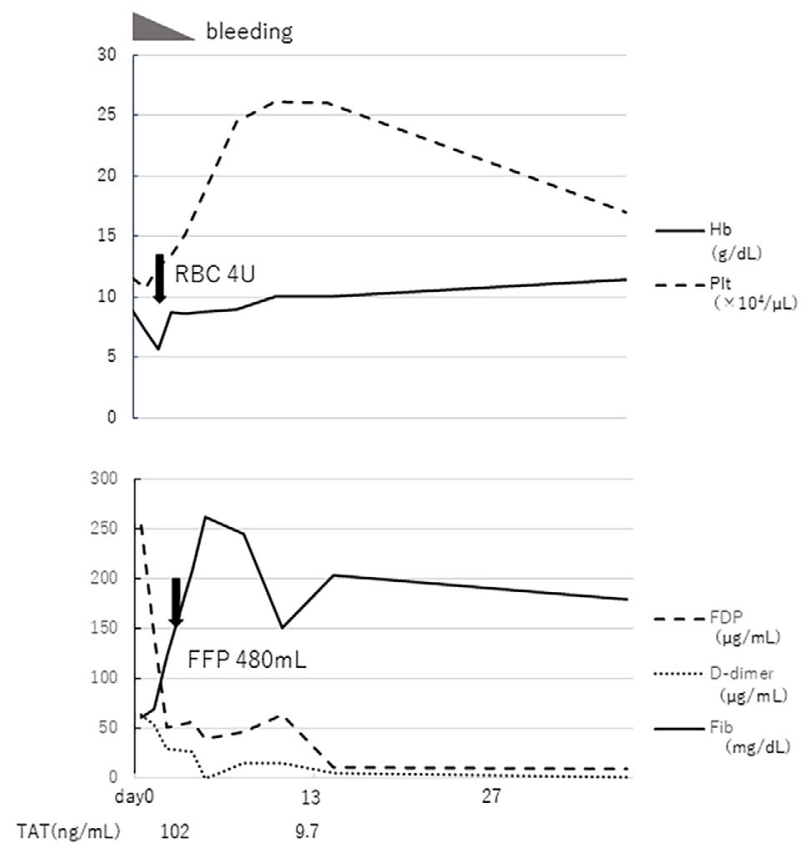

Figure. Clinical course of the case. RBC: red blood cells, FFP: fresh-frozen plasma, Hb: hemoglobin, Plt: platelet, TAT: thrombin-antithrombin complex

findings, he was finally diagnosed with DIC with enhanced fibrinolysis induced by progressive prostate cancer.

He was initially administered both tranexamic acid (TA; $1,000 \mathrm{mg} /$ day for 3 days) and carbazochrome sodium sulfonate hydrate $(50 \mathrm{mg} /$ day for 3 days) against severe intramuscular bleeding. He was then administered transfusion of red blood cells (total 4 units) as well as fresh-frozen plasma (total $480 \mathrm{~mL}$ ), since his hemoglobin level was decreased to $5.7 \mathrm{~g} / \mathrm{dL}$. Subsequently, his DIC score began to improve, and the subcutaneous bleeding gradually disappeared. He also started to take bicalutamide for the treatment of prostate cancer, and his PSA level decreased to $1,003 \mathrm{ng} / \mathrm{mL}$ at 1 month after the onset. For the meantime, DIC continued to be controllable.

\section{Discussion}

DIC is a major hemostatic complication in patients with solid tumors (2). In a previous study that analyzed a total of 1,117 patients with solid tumors, 76 were diagnosed with DIC (6.8\%), 50 (4.5\%) showed bleeding episodes, and 31 (2.8\%) showed clotting episodes (2). The distribution of hemorrhaging included oozing from venipuncture or vascular access sites, skin and mucosal surfaces, hematuria, gastrointestinal, hemoptysis, and central nervous system bleeding (2). In particular, hyperfibrinolysis has been reported in patients with acute promyelocytic leukemia (APL), abdominal aortic aneurysm, and urothelial or prostate cancer (1), leading to DIC with marked fibrinolytic activation corresponding to the activation of coagulation $(1,3)$. Regarding prostate cancer, DIC is the most frequent coagulopathy disorder, with an incidence ranging from $13 \%$ to $30 \%$; how- ever, most patients are subclinical, and only $0.4 \%-1.65 \%$ of these patients are symptomatic $(4,5)$. In the present case, we observed intramuscular bleeding, which is well known to be a main symptom of hemophilia but is very rare in solid tumors with DIC.

Our investigation failed to identify any other such cases in the English literature. These findings underscore the importance of considering the existence of serious illness, such as solid tumor, when a patient is diagnosed with DIC. Furthermore, it is necessary to take the presence of urothelial or prostate cancer into consideration when we diagnose DIC with enhanced fibrinolysis in a patient with bleeding symptoms while referencing the remarkable elevation of both TAT and PIC as well as the elevation of FDP (more dominant than D-dimer) and/or the marked decrease of fibrinogen (1).

The underlying mechanisms of DIC in patients with solid cancer are not fully understood. In general, tumor cells express various procoagulant molecules, including tissue factors, which initiate the extrinsic coagulation pathway and lead to the activation of the hemostatic system (6-9). In addition, urinary-type plasminogen activators (u-PA) produced by tumor tissues or secondary depletion of fibrinolytic inhibitors, such as $\alpha 2$-plasmin inhibitor, are thought to play important roles in the coagulation and fibrinolytic pathways, which explains the severe bleeding symptoms (10). In fact, u-PA levels were reportedly elevated in patients with prostate cancer (11), and increased u-PA can generate plasmin, leading to hypofibrinogenemia, which leads to a bleeding tendency (12). In addition, Annexin II is well known to be a cell-surface receptor for both plasminogen and its activator, t-PA, catalyzing the conversion of plasminogen to plasmin. Furthermore, these molecules are reportedly expressed by some tumor cells (13) as well as APL cells (14) and are correlated with the onset of DIC with enhanced fibrinolysis.

The basis of DIC treatment is the removal of the underlying causative factor (6). Castration therapy is indispensable for hormone-sensitive prostate cancer, as in this case; however, it is probably not sufficient to stop life-threatening episodes of bleeding in an emergency situation. TA is a wellestablished anti-fibrinolytic agent for bleeding in DIC with enhanced fibrinolysis $(1,15,16)$. It has previously been reported that TA in metastatic prostate cancer with DIC was effective for relieving the sudden onset of massive epistaxis and remarkable hematuria (16). In the present case, TA was administered to control bleeding and resulted in the improvement of the DIC score. However, TA may cause thromboembolic events in patients with enhanced fibrinolysis. Indeed, it is contraindicated in patients with APL when all-trans retinoic acid is used (1). The present patient was using TA alone without the simultaneous receipt of anticoagulant drugs, as the emergency doctor who first examined the patient was not familiar with the treatment of DIC. Although no thromboembolic events were fortunately observed, TA should be used with anticoagulant drugs, such as nafamostat mesilate or heparin $(1,17)$. 
The authors state that they have no Conflict of Interest (COI).

\section{References}

1. Asakura H. Classifying types of disseminated intravascular coagulation:clinical and animal models. Journal of Intensive Care 2: 20, 2014.

2. Sallah S, Wan JY, Nguyen NP, Hanrahan LR, Sigounas G. Disseminated Intravascular Coagulation in Solid tumors: Clinical and Pathologic Study. Thromb Haemost 86: 828-833, 2001.

3. Sallah S, Gagnon GA. Reversion of Primary hyperfibrinogenolysis in patients with hormone-refractory prostate cancer using docetaxel. Cancer Invest 18: 191-196, 2000.

4. Smith JA, Soloway MS, Young MJ. Complications of advanced prostate cancer. Urology 54 (Suppl. A): 8-14, 1999.

5. Ruffion A, Manel A, Valignat C, Lopez JG, Perrin-Fayolle O, Perrin P. Successful use of Samarium 153 for emergency treatment of disseminated intravascular coagulation due to metastatic hormone refractory prostate cancer. J Urol 164: 782, 2000.

6. Papageorgiou C, Jourdi G, Adjambri E, et al. Disseminated Intravascular Coagulation: An Update on Pathogenesis, Diagnosis, and Therapeutic Strategies. Clin Appl Thromb Hemost 24 (9_ suppl): 8S-28S, 2018.

7. Nemerson Y. Tissue factor and hemostasis. Blood 71: 1-8, 1988.

8. Levi M. Disseminated intravascular coagulation. Crit Care Med 35: 2191-2195, 2007.

9. Rickles FR, Brenner B. Tissue factor and cancer. Semin Thromb Hemost 34: 143-145, 2008.

10. Okajima K, Kohno I, Soe G, Okabe H, Takatsuki K, Binder BR. Direct evidence for systemic fibrinogenolysis in patients with ac- quired alpha 2-plasmin inhibitor deficiency. Am J Hematol 45: 1624, 1994.

11. Shariat SF, Roehrborn CG, McConnell JD, et al. Association of the circulating levels of the urokinase system of plasminogen activation with the presence of prostate cancer and invasion, progression, and metastasis. J Clin Oncol 25: 349-355, 2007.

12. Wada Y, Uchiba M, Kawano Y, et al. Severe bleeding tendency caused by a rare complication of excessive fibrinolysis with disseminated intravascular coagulation in a 51-year-old Japanese man with prostate cancer: a case report. Journal of Medical Case Reports 6: 378, 2012.

13. Hajjar KA, Menell JS. Annexin II: a novel mediator of cell surface plasmin generation. Ann N Y Acad Sci 811: 337-349, 1997.

14. Menell JS, Cesarman GM, Jacovina AT, McLaughlin MA, Lev EA, Hajjar KA. Annexin II and bleeding in acute promyelocytic leukemia. N Engl J Med 340: 994-1004, 1999.

15. Toh $\mathrm{CH}$, Alhamdi Y. Current consideration and management of disseminated intravascular coagulation. American Society of Hematology 1: 286-291, 2013.

16. Prokopchuk-Gauk O, Brose K. Tranexamic Acid to Treat Lifethreating Hemorrhage in Prostate Cancer Associated Disseminated Intravascular Coagulation with Excessive Fibrinolysis. Cureus 7: e 428, 2015.

17. Wada $\mathrm{H}$, Asakura $\mathrm{H}$, Okamoto $\mathrm{K}$, et al. Expert consensus for the treatment of disseminated intravascular coagulation in Japan. Thromb Res. 2010 125: 6-11, 2010.

The Internal Medicine is an Open Access journal distributed under the Creative Commons Attribution-NonCommercial-NoDerivatives 4.0 International License. To view the details of this license, please visit (https://creativecommons.org/licenses/ by-nc-nd/4.0/).

(C) The Japanese Society of Internal Medicine Intern Med Advance Publication 